\title{
Optimum Germination Temperature of Rudbeckia fulgida
}

\author{
Amy M. Fay ${ }^{1}$, Steven M. Still ${ }^{2}$, \\ and Mark A. Bennett ${ }^{3}$
}

Additional index words. thermogradient trials, herbaceous perennial, Black-eyed Susan

Summary. Germination trials of three seedlots were conducted over a temperature gradient for $\mathbf{1 4}$ days to determine the optimal germination temperature for the Black-eyed Susan (Rudbeckia fulgida Ait.). The optimal germination temperature for $R$. fulgida seeds was $30 \pm 1 \mathrm{C}$. All three seedlots began germination (radicle emergence) on the second day at 30.2C. By day four, all seedlots surpassed $50 \%$ germination, with three seedlots germinating $53 \%, 52 \%$, and $73 \%$. Mean germination percentages were higher between 28.3 and $32.6 \mathrm{C}$ than at temperatures above or below this range. Significantly higher germination percentages and enhanced germination rates attained at the elevated temperatures may save time, cut production costs, and decrease exposure to detrimental pre-emergent pathogenic fungi.

$R$ udbeckia fulgida Ait., the Black-eyed Susan, is a sumperennial popular in urban landscapes due to its heat tolerance, resistance to powdery mildew, ornamental qualities, and long season of bloom. However, this member of the Asteraceae family is difficult to germinate and displays variable germination rates.

Department of Horticulture, The Ohio State University, Columbus, $\mathrm{OH} 43210$.

Journal article no. 131-92. The Ohio Agricultural Research and Development Center, The Ohio State Univ. Mention of a trademark, proprietary product, or vendor does not constitute a product guarantee or warranty by The Ohio State Univ. and does not imply its approval to the exclusion of other products or vendors.

'Former Graduate Research Associate.

${ }^{2}$ Professor of Horticulture.

${ }^{3}$ Associate Professor and State Extension Specialist-Vegetable Crops. 
Current germination recommendations for $R$. fulgida vary considerably. Suggested germination regimes include 21 to $24 \mathrm{C}$ for 14 to 21 days ( $\mathrm{Nau}$, 1989; Ohio Cooperative Extension Service, 1989). Official germination requirements for $R$. fulgida have not been established (Assn. of Official Seed Analysts, 1990). The time necessary for germination delays production schedules and leads to additional production costs. The objective of this study was to determine the optimal germination temperature of $R$. fulgida.

\section{Thermogradient trials}

Experiments were conducted to determine the optimal temperature range for germination of $R$. fulgida. Three seedlots, from different seed companies, designated $\mathrm{A}, \mathrm{B}$, and $\mathrm{C}$, were used in this study. Seedlots A and B were collected in 1987 and 1990, respectively, from Switzerland, while C was collected in 1989 from Germany.

A thermogradient table (model DB 2000, van Dok \&de Boer bv, Enkhuizen) was used to create a gradient of 10 temperatures. Three individual studies were conducted. The temperature gradient for trial 1 was: 29.9, $29.5,28.2,27.0,26.1,24.9,23.8$, $22.6,21.4$, or $20.0 \mathrm{C}$. After trial 1 , germination results indicated the germination plateau had not been reached; thus, the temperature range was expanded for trial 2: $35.4,33.4,31.9$, $29.8,28.0,26.4,24.4,22.6,20.8$, or 18.8C. The widened range identified the germination plateau for trial 3 : $32.6,31.7,30.7,30.2,29.3,29.1$, $28.3,27.8,27.2$, or $26.6 \mathrm{C}$. Daily germination counts were taken for 14 days.

Thermogradient trial 1 consisted of three replications of 20 seeds for each seedlot at each of the 10 temperatures; trials 2 and 3 consisted of four replications of 50 seeds for each seedlot at each of the 10 temperatures. Seeds were placed on an 8.7-cm circle of blue blotter paper (Anchor Paper, St. Paul, Minn.) in $100 \times 15-\mathrm{mm}$ polystyrene petri dishes. The blotters were moistened initially with $\approx 7.5 \mathrm{ml}$ of distilled water, kept moist, and checked daily. Germination was defined as radicle emergence, and recorded when radicle protrusion reached $2 \mathrm{~mm}$. Seeds were kept in darkness on the thermogradient table except when moistening the substrate and taking germination counts. Data were analyzed by analysis of variante and mean separation (LSD at $P=$

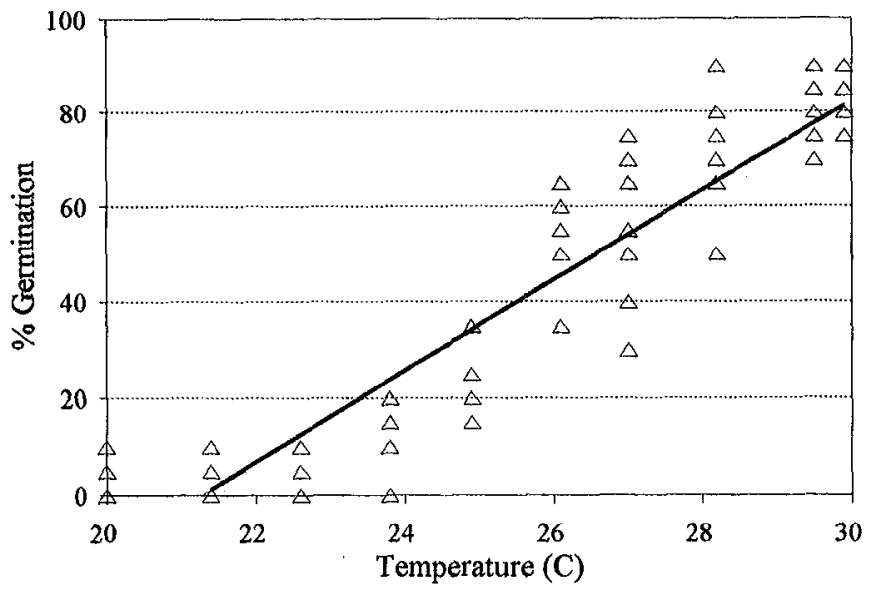

Fig. 1. Combined percent germination of three Rudbeckia fulgida seedlots from 20.0 to $29.9 \mathrm{C}$ after 14 days. Regression equation: percent germination $=-200.83+9.44 \times$ temp. $\left(\mathbf{R}^{2}=0.87\right)$.
$0.05)$ by the $F$ test. Due to few differences in seedlots, germination data were pooled and regression analyses were conducted.

Germination results of thermogradient trial 1 indicated the maximum germination plateau had not been reached because germination was continuing to increase up to 29.9 (Fig. 1). Adefinite increase, plateau, and subsequent decline in $R$. fulgda seed germination was observed as the temperature increased to $35.4 \mathrm{C}$ (Table 1, Fig. 2). Seedlot A exhibited the highest mean germination $(90 \%)$ at $31.9 \mathrm{C}$. There were no significant differences in germination response in the range from 29.8 to 33.4 C. Seedlots B and C showed no significant differences in germination over the temperature range of 28.0 to $33.4 \mathrm{C}$. If the seedlots are viewed as a group, the temperature range in which no significant differences in germination occurred was 28.0 to $31.9 \mathrm{C}$. Current recommendations for $R$. fulgida seed germination suggest placing seeds in the light at 21 to $24 \mathrm{C}$ for 14 to 21 days. The average germination across all the seedlots encompassing this temperature range was only $2 \%$ to $27 \%$ after 14 days. An increase in temperature above $22.6 \mathrm{C}$ had a significant effect on germination response. Data in Table 1 indicate the high germination percentages $(>80 \%)$ were not observed below 28.0C.

In an effort to determine the optimal germination temperature range, the temperature gradient was narrowed to 26.6 to $32.6 \mathrm{C}$. Seedlot A had a germination response of $88 \%$ to $93 \%$ over the gradient of 29.3 to $32.6 \mathrm{C}$. Results show the consistency in germination over the temperature gradient, even among different seedlots. No significant difference in germination occurred for seedlot B over the gradient 28.3 to $32.6 \mathrm{C}$, and over the gradient of 27.8 to $32.6 \mathrm{C}$ for seedlot C. As a group, the germination response for all three seedlots was not significantly different over the temperature range of 28.3 to $32.6 \mathrm{C}$. The combined germination trend across the temperature gradient of 26.6 to $32.6 \mathrm{C}$ for the three

In thermogradient trials 2 and 3 , $R$. fulgida seeds began to germinate after 2 days. The speed of germination at elevated temperatures suggests that temperature, indeed, is a critical factor for successful germination of $R$. fulgida. On the $2 \mathrm{nd}$ day at $30.2 \mathrm{C}$, seedlots $\mathrm{A}, \mathrm{B}$, and $\mathrm{C}$ all began to seedlots is seen in Fig. 3.

Table 1. Percent germination of three Rudbeckia fulgida seedlots from 18.8 to $35.4 \mathrm{C}$ after 14 days.

\begin{tabular}{|c|c|c|c|c|c|c|c|c|c|c|}
\hline \multirow[b]{2}{*}{ Seedlot } & \multicolumn{10}{|c|}{ Temperature $\left({ }^{\circ} \mathbf{C}\right)$} \\
\hline & 18.8 & 20.8 & 22.6 & 24.4 & 26.4 & 28.0 & 29.8 & 31.9 & 33.4 & 35.4 \\
\hline & \multicolumn{10}{|c|}{ Germination (\%) } \\
\hline A & $0 \mathrm{a}^{\mathrm{z}}$ & $1 \mathrm{ab}$ & $9 \mathrm{~b}$ & $23 \mathrm{c}$ & $53 \mathrm{~d}$ & $81 \mathrm{e}$ & 89 ef & $90 \mathrm{f}$ & $83 \mathrm{ef}$ & $48 d$ \\
\hline B & $0 \mathrm{a}$ & $0.5 \mathrm{a}$ & $5 a$ & $16 \mathrm{~b}$ & $55 \mathrm{~d}$ & $81 \mathrm{e}$ & $83 \mathrm{e}$ & $83 \mathrm{c}$ & $77 \mathrm{e}$ & $39 c$ \\
\hline $\mathrm{C}$ & $0 \mathrm{a}$ & $4 a$ & $7 \mathrm{a}$ & $41 b$ & $56 \mathrm{c}$ & $85 \mathrm{e}$ & $87 \mathrm{e}$ & $83 \mathrm{c}$ & $80 \mathrm{e}$ & $64 \mathrm{~d}$ \\
\hline Mean & $0 \mathrm{a}$ & $2 \mathrm{ab}$ & $7 b$ & $27 \mathrm{c}$ & $55 \mathrm{~d}$ & 82 ef & $86 \mathrm{f}$ & $85 \mathrm{cf}$ & $80 \mathrm{e}$ & $50 \mathrm{~d}$ \\
\hline
\end{tabular}

${ }^{z}$ Mean separation using $L S D$ within horizontal rows by $F$ test, $\mathrm{P}=0.05$. 


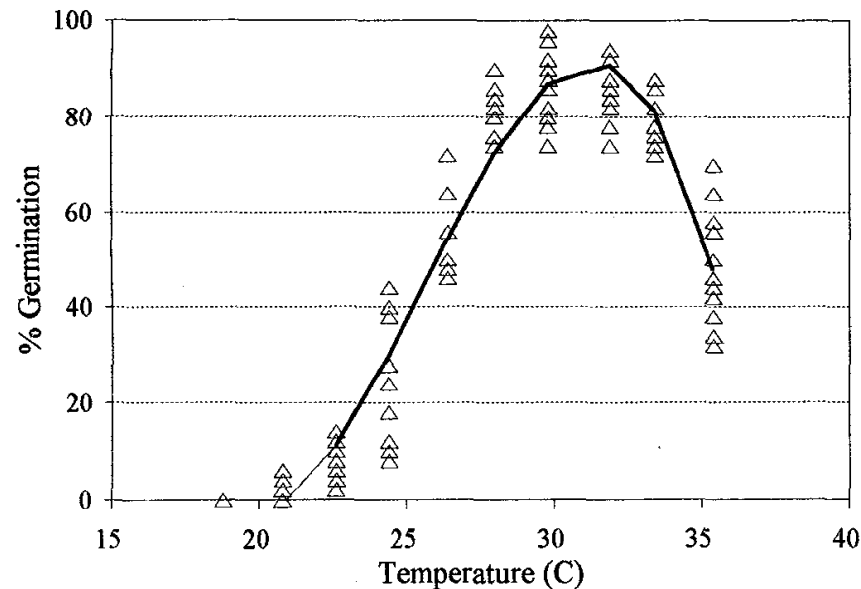

Fig. 2. Combined percent germination of three Rudbeckia fulgida seedlots from 18.8 to $35.4 \mathrm{C}$ after 14 days. Regression equation: percent germination $=-0.12 \times$ temp. ${ }^{3}+9.51 \times$ temp. ${ }^{2}-230.94$ $\times$ temp + 1803.95. $\left(\mathrm{R}^{2}=0.95\right)$.

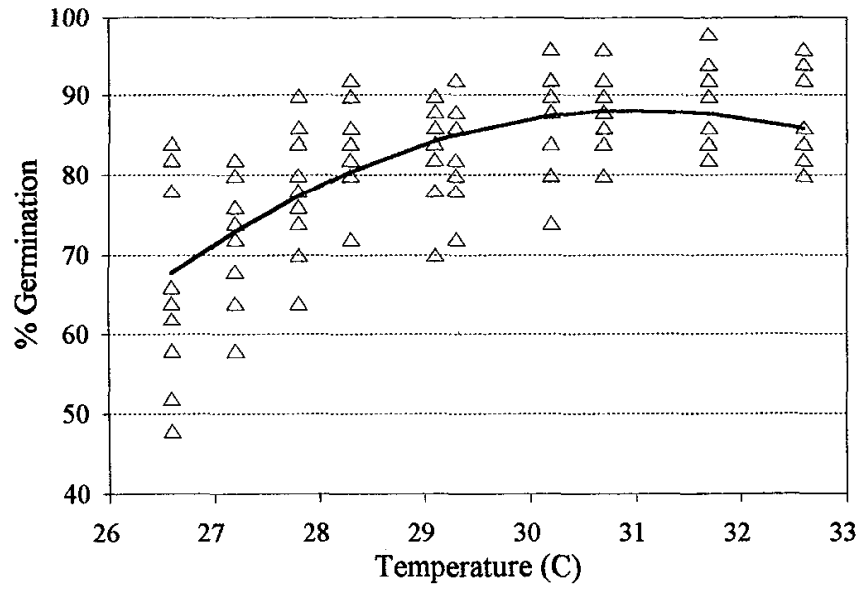

Fig. 3. Combined percent germination of three Rudbeckia fulgida seedlots from 26.6 to $32.6 \mathrm{C}$ after 14 days. Regression equation: percent germination $=-1.03 \times$ temp. ${ }^{2}+63.85 \times$ temp. 903.72. $\left(\mathrm{R}^{2}=0.49\right)$.

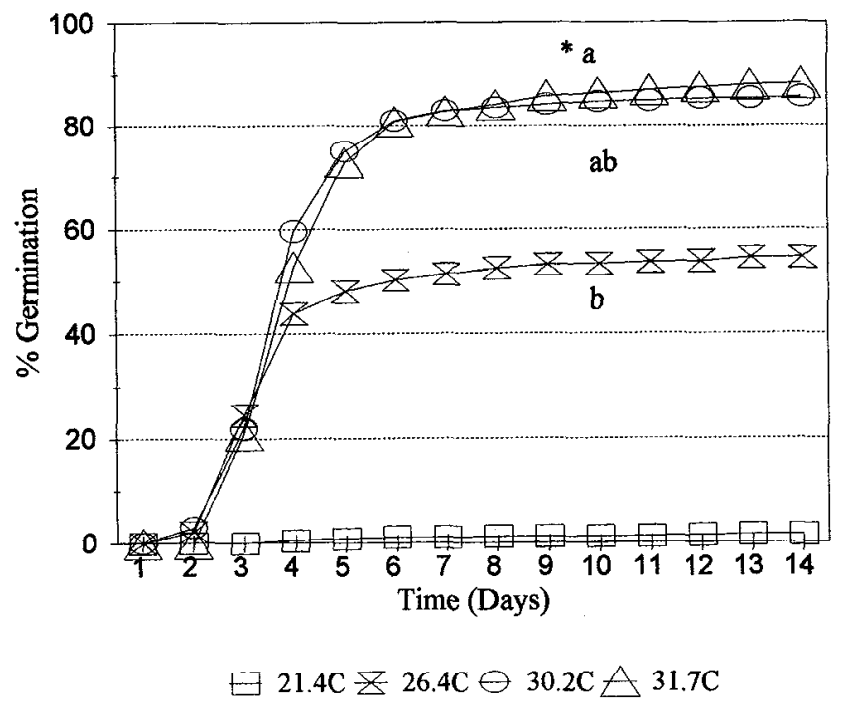

Fig.4. Combined percent germination of three Rudbeckia fulgida seedlots at germination temperatures of 21.4, 26.4,30.2, or 31.7C. Mean time to germination (MTG) analyzed by mean separation using LSD.

*Significant at $\mathbf{P}=0.05$.

germinate. After 4 days at $30.2 \mathrm{C}$, seedlots A, B, and C germinated 53\%, $52 \%$, and $73 \%$, respectively. At $31.7 \mathrm{C}$, seedlots $\mathrm{A}, \mathrm{B}$, and $\mathrm{C}$ reached $78 \%$, $58 \%$, and $82 \%$ germination within 5 days after placement on the thermo- gradient table. Nine days at this temperature resulted in $90 \%$ and $88 \%$ germination for seedlots $\mathrm{A}$ and $\mathrm{C}$, respectively. The rapidity of germination at these elevated temperatures can be compared to germination at 26.46 . Four days at 26.46 resulted in $42 \%$, $37 \%$, and $52 \%$ germination for seedlots $\mathrm{A}, \mathrm{B}$, and $\mathrm{C}$ respectively. Seedlot C exceeded $50 \%$ germination on day 4 , while seedlots A and B exceeded 50\% germination on day 8. After 9 days, seedlots $\mathrm{A}, \mathrm{B}$, and $\mathrm{C}$ germinated $51 \%$, $53 \%$, and $55 \%$, respectively. Viewing the seedlots together, the mean times to germination (MTG) at 26.4, 30.2, and $31.7 \mathrm{C}$ were $4.0,4.2$, and 4.6 days, respectively (Fig. 4). At $21.4 \mathrm{C}$, a temperature in the range currently recommended in seed catalogs for R. fulgida germination, the seedlots ranged from $0 \%$ to $4 \%$ germination after 14 days.

The current recommended temperature of $21 \mathrm{C}$ is not sufficient for $R$. fulgida seed germination. These studies indicate that the optimal germination temperature range for $R$. fulgida is 28.0 to $32.0 \mathrm{C}$, with the highest germination at $\approx 30 \pm 1 \mathrm{C}$. Higher germination percentages and germination rates at the elevated temperatures may save time, cut production costs, and decrease the time seeds are exposed to detrimental pre-emergent pathogenic fungi. This finding indicates that recommended germination temperatures for other genera and species may be faulty and require additional screening. Further testing also is needed to determine germination temperature differences for seedlots of a given cultivar and cultivar variationwithin a given seedlot.

\section{Acknowledgment}

We gratefully thank Geo. J. Ball Seed Co., West Chicago, Ill., and Klaus R. Jelitto Perennial Seed Co., Hamburg, Germany, for the contribution of two of the seedlots studied in this research.

\section{Literature Cited}

Association of Official Seed Analysts. 1990. Rules for testing seeds. L. Wiesner (ed.). J. Seed Technol. 12(3):18-72.

Nau, J. 1989. Ball culture guide-The encyclopedia of seed germination. G.J. Ball, Inc., West Chicago, Ill.

Ohio Cooperative Extension Service. 1989. Tips on growing potted perennials and biennials. H.K. Tayama (ed.). The Ohio State Univ. Bul. FP-766. 